\title{
Organización obrera y políticas laborales en las minas de cobre de México y Chile, 1900-1940
}

\author{
Workers' organization and labor policies \\ in Mexico's and Chile's copper mines, 1900-1940
}

\author{
Rosario Margarita Vasquez Montaño* (D https://orcid.org/0000-0002-5605-7749
}

\section{Resumen}

En el artículo se analiza la conformación y el desarrollo de la minería de cobre en México y Chile durante la primera mitad del siglo XX. Es una exploración no acabada y responde a la necesidad de estudiar los procesos históricos regionales, desde la perspectiva comparada, para reconocer periodos ligados a procesos económicos y políticos más amplios. A través de la historia de la organización sindical, la cultura obrera y las políticas laborales de los gobiernos de la época es posible advertir similitudes entre las experiencias en los minerales de los dos países. Asimismo, se reconocen los caminos diferenciados respecto al activismo sindical, las influencias ideológicas y políticas y las formas de negociación de los trabajadores con el Estado. La condición multinacional de las mineras en México y Chile permitió la conformación de los enclaves, con características similares en su conformación primaria, pero con diferencias al ser trasformados por los trabajadores en su diálogo y confrontación con las empresas y el Estado.

Palabras clave: minería; cobre; relaciones laborales; movimientos sociales; company town; política gubernamental; Chile; México.

\begin{abstract}
The article analyzes the formation and development of copper mining in Mexico and Chile during the first half of the 2oth century. It is an unfinished exploration and responds to the need to study regional historical processes from a comparative perspective in order to recognize periods related to broader economic and political processes. By examining the history of union organization, working-class culture and labor policies of the governments of the time, it is possible to note similarities between the experiences of both countries' mining sites. In addition, differentiated pathways concerning union activism, ideological and political influences and the workers' forms of negotiation with the State are recognized. The multinational nature of mining companies in Mexico and Chile allowed the formation of enclaves with similar characteristics in their primary stage, but with differences after being transformed by workers while negotiating with and confronting firms and the State.

Keywords: mining; copper; labor relations; social movements; company town; government policy; Chile; Mexico.
\end{abstract}

Cómo citar:Vasquez Montaño, R. M. (2019). Organización obrera y políticas laborales en las minas de cobre de México y Chile, I9001940. región y sociedad, 31, e I040. doi: I0.22198/rys2019/3 I/ 040

* El Colegio de México. Carretera Picacho-Ajusco 20, Fuentes del Pedregal, C. P. 14110. Ciudad de México, México. Correo electrónico: mgl.vasquez@gmail.com

Recibido: 14 de febrero de 2018

Aceptado: 17 de abril de 2018

Liberado: 6 de marzo de 2019 


\section{Introducción}

Al trazar la historia del trabajo y los trabajadores en América Latina es inevitable pensar en factores contextuales y estructurales que hacen posible dibujar líneas a veces paralelas y otras distantes de lo acontecido en torno al tema en países de la región. Para explicar la formación del proletariado mediante la industrialización, la inversión de capital, la organización y la acción obrera se debe observar un escenario más amplio en el que las ideas sobre el trabajo y los trabajadores se han explicado como parte primordial de la sociedad y de la política, sobre todo después de la revolución industrial. Aquí se presenta un acercamiento comparativo entre la condición del trabajo en las minas de cobre, con el foco de atención en México y Chile, que tienen tradición cuprífera. Aunque el mayor énfasis está puesto en el caso mexicano, también hay alusiones al comportamiento del trabajo y los trabajadores chilenos. A pesar de las diferencias consistentes entre los dos países, se pueden encontrar ciertos paralelismos que vale la pena mencionar, en especial desde principios del siglo XX a la década de 1940.

En la minería del cobre se analiza el desarrollo del movimiento obrero en estos espacios de economía de enclave típica, el grado de autonomía que ejercieron por medio de ciertas posturas ideológicas, como el anarquismo y el comunismo, la manera en que la lucha y la resistencia de los mineros contribuyó a su reconocimiento y a la formación de un sindicalismo organizado y estructurado, así como el grado en que tales sindicatos fueron cooptados, en mayor o menor medida, por el Estado y la centralización sindical y cómo esta característica del sindicalismo latinoamericano influyó en las acciones posteriores de los obreros de las minas.

\section{La minería del cobre. Desarrollo industrial y capital extranjero}

Para adentrarse en el tema de los trabajadores del cobre, es primordial explicar de manera sucinta las condiciones económicas y materiales de la conformación de la mina como un lugar de trabajo intensivo. El origen de estos espacios, tanto en México como en Chile, está vinculado con las inversiones del capital extranjero y su expansión, traducido en industrias trasnacionales que se establecieron en regiones o zonas de países cuya historia era poco fructífera en la explotación de minerales (Orellana, 2004; Romero, 2001). A finales del siglo XIX los inversionistas extranjeros expresaron e hicieron efectivo su interés por asentar filiales de sus consorcios en América Latina, según conceptos económicos y de mercado similares.

Fue el capital estadounidense el que se estableció con más ímpetu en la minería del cobre; lo hizo en las minas de Pilares de Nacozari y Cananea, en el estado de Sonora, México, y en El Teniente, Potrerillos y Chuquicamata, en Chile. Cabe señalar que en este mapa de inversión se encontraba la mina El Boleo, en 
Baja California, que operaba con fondos franceses. El impulso a la minería del cobre era "un esfuerzo empresarial de sustituir las faenas de extracción individual por un interés por desarrollar lo que se conoce como explotación de escala" (Orellana, 2004, p. 179). Una vez establecidos, los inversionistas implementaron un sistema de modernización en las técnicas de extracción mineral, así como en la construcción de concentradoras, vías angostas de ferrocarril para trasladar el material, la apertura de otras minas, la conformación de una red de mercado trasnacional en la frontera sonorense y el trasporte marítimo para El Boleo y las minas chilenas, por su cercanía a las costas del Pacífico.

En México las minas de cobre más importantes se asentaron en el noroeste. Los "tres grandes tigres del norte": El Boleo, Cananea y Pilares de Nacozari se consolidaron como las principales productoras nacionales de cobre en la época porfirista (Romero, 2001, p. 216). Con el auspicio del gobierno de Porfirio Díaz se abrieron las puertas a estas compañías a través de contratos, el fomento a la industrialización y la colonización (Romero, 2001, p. 280). En 1885, la Casa Rotschild, de capital francés, se estableció en la parte media de la península de Baja California (Romero, 1991, p. 55), y le siguió Pilares de Nacozari con The Moctezuma Copper Company, en 1897, como filial de la Phelps Dodge (empresa que contaba con una trayectoria de explotación cuprífera en Arizona) (Oviedo y Ríos, 1997, p. 17). La Cananea Consolidated Copper Company se fundó con el apoyo financiero de William Cornell Green, en 1899; aunque ocho años después la Anaconda Copper Company adquirió la mayoría de las acciones para convertirla en una sucursal más de su emporio minero (Sariego, 1988, pp. 39 y 48). Era un imperio corporativo que tenía compañías subsidiarias y líneas de mercado minero en Estados Unidos, México y Chile (Vergara, 2008, p. 15).

Por la misma época el capital estadounidense también llegó a Chile. Las minas de cobre El Teniente, Chuquicamata y Potrerillos -tomadas como referente en esta comparación-, nacieron con características similares a las de Sonora y Baja California. Entre 1904 y 1911 la familia Guggenheim, ${ }^{1}$ dueña de la empresa Kennett Copper Company, ${ }^{2}$ adquirió El Teniente y Chuquicamata (Miller, 1998, p. 26). A la Anaconda Copper Company, la cual comenzó a explorar e invertir en las minas chilenas desde 1910, se le cedieron los derechos de Potrerillos, a través de la Andes Copper Mining Company (Vergara, 2008, p. 3), y en 1923 adquirió los derechos y el control de la Chile Exploration Company, que explotaba la mina Chuquicamata (Zapata, 1979, p. 20).

Las dos compañías trasnacionales monopolizaron la industria del cobre en Chile (Vergara, 2008, p. 17). El desplazamiento de empresas, como la Anaconda Copper Company era parte de un proceso de expansión del mercado minero a gran escala. Además de ello, se puede trazar la ruta temporal del surgimiento de dichas minas. Por otra parte, y sin dejar de lado las explicaciones de tipo estructural, es paradójico -o quizá solo circunstancial- que el establecimiento

1 Esta familia estadounidense compró varias minas en Chile y México. Una de las primeras inversiones que intentaron echar andar fue la de Pilares de Nacozari, en Sonora, pero con muy poco éxito, por lo que la vendieron a Phelps Dodge (Oviedo y Ríos, 1997, p. 17; Romero, 2001, p. 219).

2 Según Miller, para 1915, los Guggenheim también habían adquirido minas de cobre en Alaska, Utah, Nevada, Arizona y Nuevo México. 
de las minas en Chile (a excepción de El Teniente) ocurriera cuando en México se desarrollaba una lucha armada. Sin ser este un factor preponderante, llama la atención que aun cuando en general a las minas de cobre en el noroeste mexicano no les perjudicó la guerra, el hecho de tener otras bases de producción cuprífera les daba un respiro.

Figura 1. Principales minas de cobre en el noroeste de México

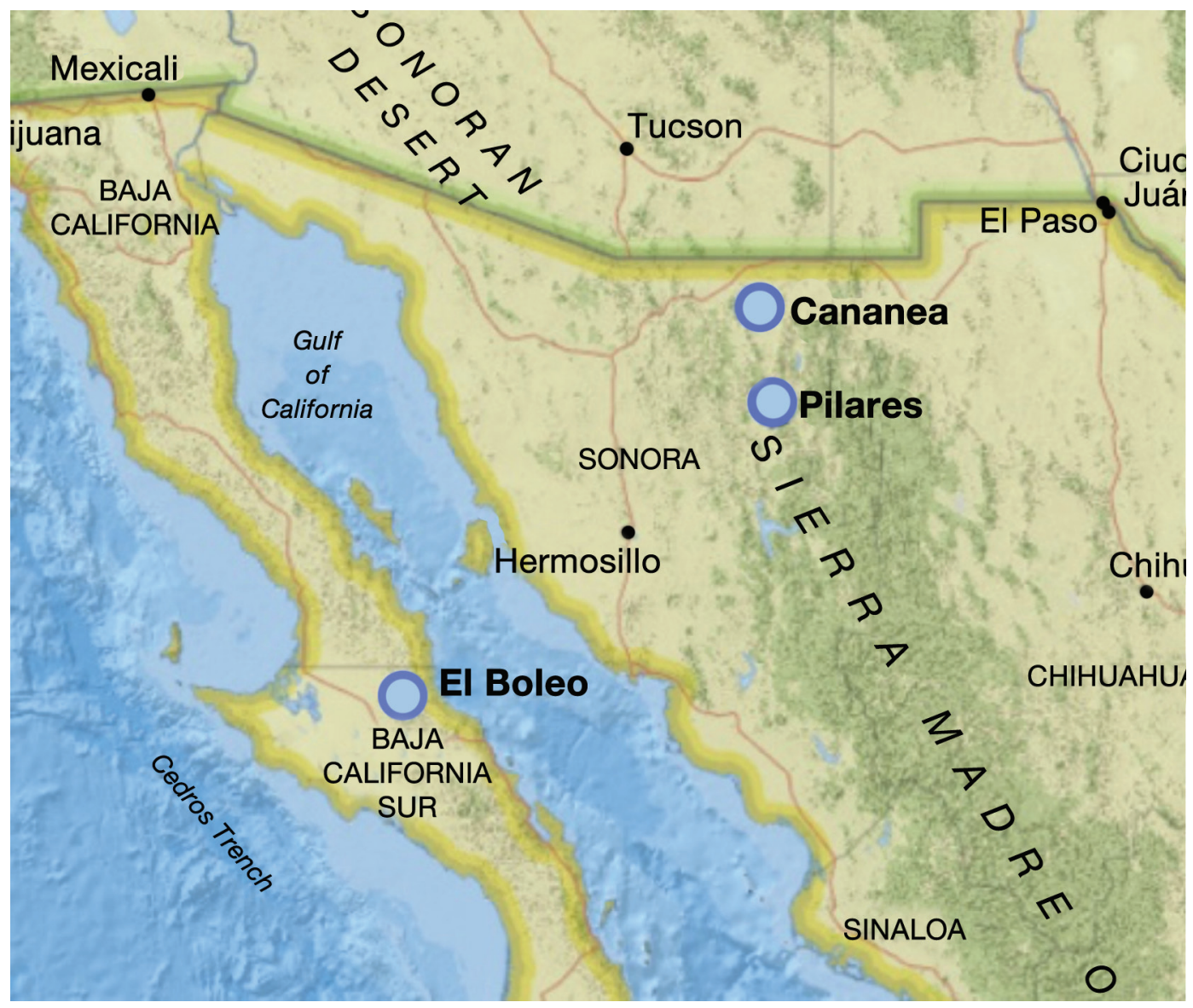

Fuente: elaboración propia, mediante MapMaker de National Geographic (http://mapmaker.nationalgeographic.org).

La explotación y el beneficio del cobre respondían a un mercado externo que marcaba los flujos y los ciclos de los precios y de la producción propia. Por medio de una economía de enclave, la industria minera se desvinculaba casi por completo de la economía nacional en la cual estableció sus compañías de explotación. En México y Chile el metal rojo se convirtió en materia prima estratégica, sobre todo en momentos coyunturales como las dos guerras mundiales; lo que llevó a intensificar la producción y a que las empresas tendieran a mantener una mano de obra estable y constante. 
Figura 2. Principales minas de cobre en Chile

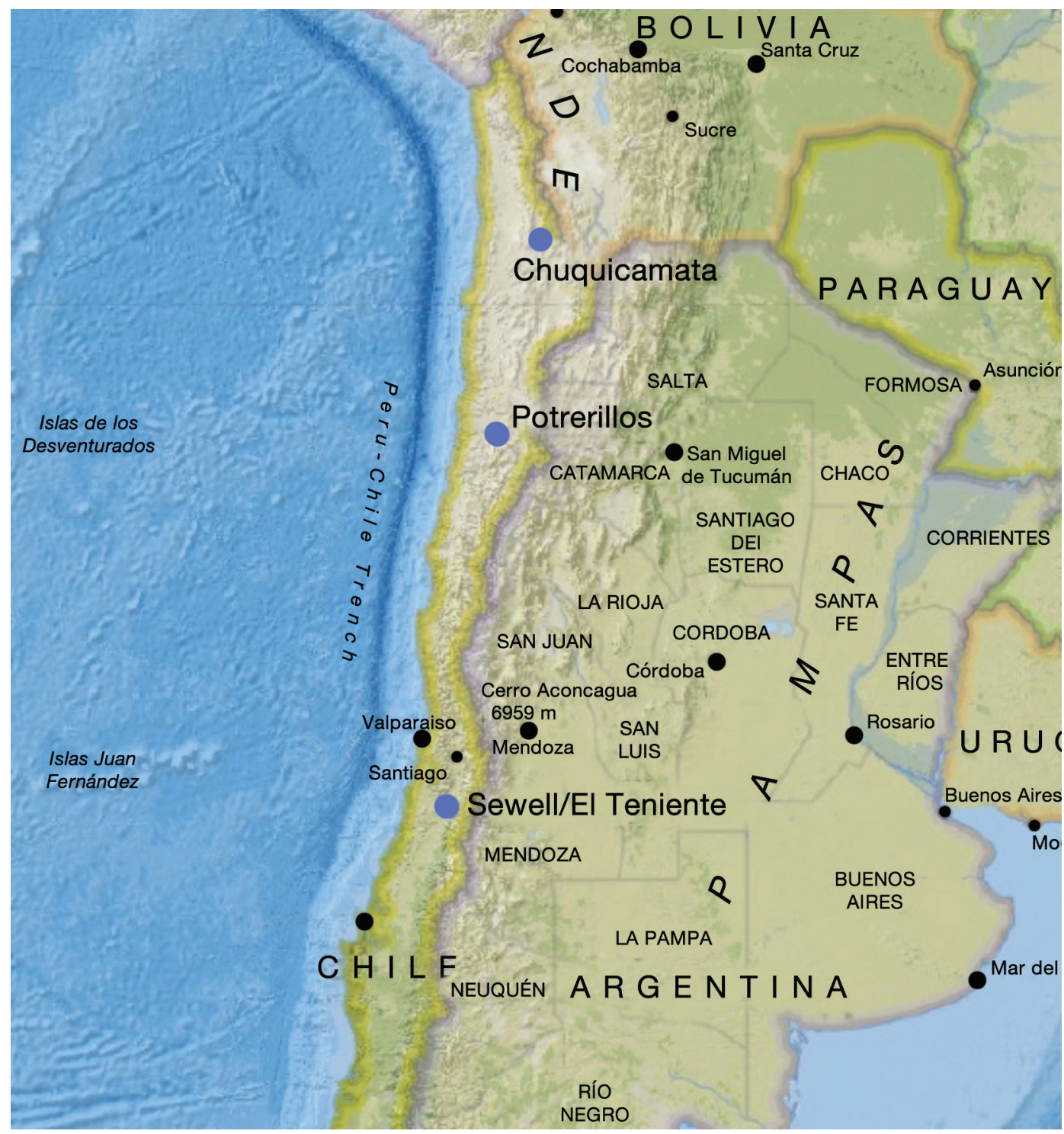

Fuente: elaboración propia, mediante MapMaker de National Geographic (http://mapmaker.nationalgeographic.org).

\section{Los enclaves y la formación del proletariado minero}

La consolidación material y laboral de las empresas fue resultado de la conformación del propio espacio minero mediante una estructura de enclave. El carácter aislado, la ausencia de condiciones mínimas para la producción, así como la necesidad de retención de la mano de obra generaron un impulso por forjar dinámicas espaciales bajo la tutela de la dirección de las compañías mi- 
neras (Zapata, 1977, pp.720-722). En México, en parte, fue posible gracias a las facilidades otorgadas por el Estado y las leyes promotoras de la inversión y la colonización. Además, la construcción de los company towns o "campamentos" se orientó a la necesidad de "cuidar una fuerza de trabajo específica en muchas partes escasa y también inflamable” (Cárdenas, 1997, p. 143).

Las mineras se enfrentaron a la falta de mano de obra, compuesta mayoritariamente por trabajadores sin experiencia en las artes de la minería, provenientes de áreas rurales que, para atraerla, con frecuencia utilizaban el método de enganche. En el noroeste mexicano los trabajadores calificados llegaron de antiguos reales de minas de Hidalgo, Guanajuato y Zacatecas (Sariego, 1998, p. 77). En Chile, en el caso de El Teniente los trabajadores fueron enganchados de zonas agrícolas, así como de las ciudades, puertos y otras minas, como las de nitrato (Miller, 1998, p. 33). Thomas Miller señala las vicisitudes de la directiva de la compañía para conseguir mano de obra estable, al grado de que la primera huelga de los obreros, en 1911, fue porque rechazaban las políticas de la empresa que les restringía el derecho de dejar el empleo de manera libre e independiente (Miller, 1998, p. 50).

La mano de obra en las minas fue fluctuante hasta que los obreros lograron establecerse y organizarse en mutuales y sindicatos. Llama la atención el retrato de la movilidad obrera en las minas de cobre del noroeste de México. Según Romero, se conformó un corredor laboral que fluía del centro al norte, pero también entre los minerales de la región (2001, p. 339). No es extraño que debido a lo poroso de la frontera, los trabajadores mexicanos y los estadounidenses fueran y vinieran a lo largo de la red de minas establecidas entre Sonora y Arizona.

En Cananea ya funcionaba una mina, a las órdenes de William C. Green, cuando llegó la Anaconda Copper Company. La distribución del área habitacional en la ciudad era jerárquica, los mejores lotes se destinaron a los directivos y los empleados estadounidenses, después estaban las áreas públicas municipales y en la zona periférica los barrios o torreones habitados por los obreros, donde la dotación de servicios era mínima (Sariego, 1988, p. 90). La distribución del espacio habitacional tuvo que ver con la designación temprana de Cananea como municipio, en 1901, lo que de alguna manera propició que la empresa delegara a las autoridades los aspectos sociales y de vivienda.

Los directivos de la compañía controlaron toda la organización del espacio en El Boleo y en Pilares de Nacozari. Fue en esta última mina donde todo el espacio se construyó de manera más sistemática y jerarquizada, ya que su dinámica social estuvo bajo la tutela empresarial. Además, en los primeros años de la Moctezuma Copper Company, no existió un municipio constituido legalmente como en Cananea. Tuvieron que pasar los años de la revolución y que Venustiano Carranza emitiera un decreto en el que ordenaba una ley de expropiación a los fundos mineros, para que se convirtieran en municipios. Lo mismo sucedió con El Boleo, en 1917 (Romero, 1991, p. 183).

En las minas de Chile, a través de su Departamento de Bienestar, se crearon regulaciones internas para mantener el control de los trabajadores, tanto en el espacio laboral como en el privado. Fueron significativas las inspecciones que hacía el departamento en las casas de los obreros, en busca de alcohol y bienes 
robados, como medida de vigilancia o con el afán de proteger la propiedad de la empresa (Miller, 1998, p. 53; Vergara, 2008, p. 40). Además, en El Teniente y Chuquicamata surgió un sistema de espionaje, controlado por la empresa, alrededor de las actividades y reuniones de las organizaciones obreras en el lugar (Miller, 1998, p. 54; Zapata, 1979, p. 21).

Los campamentos se caracterizaron por ser espacios cerrados y jerarquizados. Las compañías hacían evidente las diferencias de clase a través de la distribución urbana del enclave: por un lado se hallaba la población obrera nacional frente a la estadounidense $y$, por otro, los trabajadores de las minas estaban separados de los empleados de "cuello blanco", ya fueran extranjeros, característica de las minas mexicanas, o nacionales, como en Potrerillos (Vergara, 2008, p. 51). En la cúspide de la organización espacial del mineral se encontraban los directivos de la empresa. La producción y reproducción del trabajo iba aparejada con medidas de distribución espacial, por pautas de tipo moral, de educación e higiene.

El concepto de company town, de alguna manera, ha velado la intensidad de las relaciones sociales y políticas alrededor de la vida de estos espacios que se constituyeron en comunidades populosas. En los resquicios de esa vida de control permanente germinaron posiciones cercanas al sindicalismo. Es decir, fue en estos lugares donde se desarrolló una conciencia de clase en la que el origen de los trabajadores y el recurso de la solidaridad, además de elementos de tipo ideológico -que rompieron el carácter estrictamente cerrado de las minasconfiguraron el discurso y la organización obrera frente al capital extranjero (Zapata, 2013, p. 47).

En Chile, al igual que en El Boleo y Pilares de Nacozari, los campamentos surgieron de la nada, en sitios aislados en los que trabajadores y habitantes experimentaron una dinámica aparentemente disociada del contexto regional y nacional. Los obreros se enfrentaron a las dificultades de la movilidad, pues las empresas controlaban los únicos medios de trasporte, los barcos y el ferrocarril, según el caso, lo que coadyuvó a la conformación de una masa obrera a través de las medidas restrictivas de las empresas y la resistencia de los trabajadores.

\section{De la acción directa al sindicalismo obrero}

Además de la cohesión social que se gestó entre la comunidad obrera, para los directivos de las compañías fue casi imposible detener la ola ideológica que llegaba a los pueblos mineros los cuales habían sido diseñados en función de la explotación masiva de cobre y no dejaban lugar para la organización y demandas de los trabajadores. La influencia del anarcosindicalismo y del Partido Liberal Mexicano (PLM) fue importante para las primeras acciones de los obreros en las minas de Baja California y el norte de Sonora (Romero, 1991, p. 240). Por ejemplo, el programa del PLM de 1906 calzó bien con las necesidades y la incipiente lucha obrera en estas minas. La crítica a las condiciones laborales, la apela-

ción a una especie de nacionalismo que reivindicaba la posición del trabajador mexicano frente al capitalista extranjero, así como las estrategias de la acción 
directa y la clandestinidad fueron elementos que conformaron la base política e ideológica de la organización de los trabajadores de esta región (Sariego, 1988, p. 129).

En el mismo tenor, los vínculos con el sindicalismo estadounidense representado en la Western Federation of Miners, uno de los sindicatos más emblemáticos de las minas de cobre en Arizona, fue importante para el incipiente movimiento obrero en Sonora. Dichos vínculos se establecieron por el flujo laboral que había en el límite entre las dos entidades fronterizas. Los trabajadores de Estados Unidos “eran el único núcleo obrero organizado en la población y al ser los autores de las primeras luchas obreras que existieron en Cananea" (Sariego, 1988, p. 126).

También estaban las agrupaciones de tipo mutualista y las mancomunales, que en la historiografía sobre el tema están consideradas como un antecedente de los sindicatos mineros, aunque existen posturas encontradas al respecto. Para el caso de Cananea, Sariego señala que el anarcosindicalismo fue la base de las primeras agrupaciones de los trabajadores, frente a la ausencia de una tradición mutualista, que se debía a la carencia de una práctica minera previa, a la desaparición de unos oficios y a la creación de otros (Sariego, 1988, p. 130). Por su parte, Romero resalta que en El Boleo las mutuales fueron muy importantes para la organización obrera. En 1916 se fundó la Sociedad Mutualista Progreso -por los empleados- y le continuó la Sociedad Mutua Obreros “Aquiles Serdán”. Desde su origen, la primera contó con el beneplácito de la empresa y las autoridades del Distrito de Baja California (Romero, 1991, p. 241). La segunda fue mal vista por los directivos, porque era una filial de la matriz en Cananea, con "fuerte raigambre magonista", conformada por mineros, maquinistas y mecánicos (Romero, 1991, p. 243).

En Chile también existieron estas particularidades, y es significativo que el anarquismo, a diferencia del caso mexicano y con una presencia temprana y mejor consolidada, se adhiriera entre los trabajadores de las ciudades y los puertos, y también que fuera vigoroso en los primeros años de las organizaciones obreras, sobre todo entre 1893 y 1920 (Grez, 2007, p. 58). A la zona minera del cobre los flujos de la agitación ácrata llegaron por vía de los trabajadores del salitre, quienes integraban la mano de obra de las minas cupríferas.

En la "fase heroica del sindicalismo chileno", (Grez, 2007) el anarquismo propició las condiciones para la consolidación de las confederaciones. El aletargamiento de esta postura y su desvanecimiento tuvo que ver con la consolidación del marxismo como camino ideológico, y con la formación de partidos de raigambre socialista y comunista en la primera y segunda décadas del siglo XX que se lograron consolidar mediante su relación con el movimiento obrero. En el caso mexicano, el retraimiento del anarquismo, como influencia y presencia real entre los obreros, tuvo que ver con la persecución que sufrieron sus líderes en la etapa porfirista y también con los primeros gobiernos de la revolución. ${ }^{3}$ Asimismo, cabe preguntarse si el fin último o meta de los dirigentes del anarquismo

Lázaro Gutiérrez de Lara fue asesinado por órdenes de Plutarco Elías Calles; era un connotado líder anarquista y socialista cuya presencia fue medular en los conflictos obreros de Cananea, a principios del siglo XX (Gutiérrez, 2010). 
mexicano era similar a la de los trabajadores. Si la relación con el sector obrero fue la misma o si al entrar en una etapa incipiente de reconocimiento formal, a partir de la promulgación de leyes laborales, los vínculos entre los dirigentes anarquistas y el movimiento obrero se fueron desdibujando.

Tanto en Chile como en México, el decaimiento del anarquismo, a principios de la década de 1920, coincidió con un cambio en el discurso gubernamental hacia la idea del trabajo y los trabajadores, que se reflejó en la promulgación de leyes sociales y laborales, así como en la apertura política a la conformación de un sindicalismo legal ${ }^{4}$ (Grez, 2007, p. 17; Sariego, 1988, p. 174). No obstante, estas disposiciones abrieron la puerta a las contradicciones y las presiones propiciadas por la intervención del Estado en las relaciones capital-trabajo, en un intento por reducir la tensión producida entre estas dos figuras de poder en los enclaves mineros.

\section{¿Beneficios en políticas laborales o el camino a la cooptación?}

Con la segunda década del siglo XX en puerta, la existencia de una fuerza de trabajo ya arraigada en los centros mineros, compuesta por sectores calificados en el proceso de trabajo, y la consolidación de líderes sindicales, salidos del socavón de las minas, que sustituyeron a los precursores anarquistas de principios de siglo, fueron factores que trazaron el camino de la sindicalización de los mineros del cobre (Romero, 1991, p. 255).

En México, el movimiento armado, que inició en 1910, dirigió la mirada hacia el sector obrero y campesino como base de legitimidad y distanciamiento del antiguo régimen. El largo proceso de resistencia (huelgas, pronunciamientos, publicaciones periódicas y la acción directa) por parte de los sectores obreros del país fue un factor de presión para impulsar las medidas legales tempranas además de los intentos de los primeros gobiernos de la revolución por imponer una política nacionalista sobre la minería. En el rubro laboral, la promulgación del Reglamento de Policía y Seguridad, en 1912, evidencia las primeras incursiones del Estado en los temas relacionados con la producción y las condiciones de vida del sector minero (Sariego, 1988, p. 52).

La implementación de dicho reglamento no fue posible por los sucesos políticos y de guerra que siguieron a 1912, aunado al poder que aún preservaban las compañías mineras. Durante el conflicto armado la producción minera no fue trastocada de manera contundente, como el caso de la Cananea Copper Company (Sariego, 1988, p. 50), aunque sí fue un foco de reacciones revolucionarias. En contraste, en El Boleo solo se experimentaron rachas de movilización. La población de estos lugares pasó los años aciagos de la lucha armada "trabajando en las minas; produciendo cobre en la fundición y observando las pugnas

4 Para Sariego (1988), la huelga de 1917 marca el final de la acción directa y el anarcosindicalismo en Cananea, y el comienzo de una "nueva ideología obrerista" sustentada en vínculos y tratos con los caudillos de la revolución. 
revolucionarias. Iniciaban el mes con soldados adictos al villismo y cerraban con militares que portaban la inscripción 'Viva la Constitución'[...]” (Romero, 1991, p. 178). Lo que contribuyó a que disminuyera la movilidad de la población en el lance revolucionario fue el aislamiento real, así como el control férreo de la empresa francesa sobre sus propiedades.

Con la promulgación de la Constitución Política de los Estados Unidos Mexicanos de 1917, y el artículo 123, nació un marco político-jurídico que definió las relaciones obrero-patronales con la intervención gubernamental, y convirtió en derechos algunas de las demandas que los trabajadores habían exigido años atrás. Estas medidas legales respaldaron o, en su caso, matizaron las reformas laborales implementadas en varios estados, entre 1914 y 1916 . Como ocurrió con los regímenes sonorenses de Plutarco Elías Calles y Adolfo de la Huerta, sus disposiciones fueron un ensayo tanto para el gobierno local como para los obreros en materia laboral (Sariego, 1988, p. 149). En parte, este movimiento político estratégico coadyuvó al detrimento paulatino del anarcosindicalismo entre los trabajadores.

La creación de las juntas de conciliación y arbitraje locales y el reconocimiento de las primeras organizaciones sindicales abrieron las negociaciones entre capital y trabajo. En la práctica, este periodo fue más positivo para las empresas que para los trabajadores, ya que muchas veces los conflictos se resolvieron a favor de las primeras, gracias a los nexos entre ellas y los representantes de los gobiernos locales. Tal como sucedió en El Boleo cuando, en 1919, entró en vigor el Reglamento de Trabajo aprobado por el gobernador del territorio de Baja California y el director de la compañía. La intención era aumentar la producción de cobre con pocos trabajadores y el mismo salario e imponer multas a quienes no cumplieran con tal disposición (Romero, 1991, p. 205), lo cual más que reglamentar la vida laboral en beneficio de los obreros los obligaba a cumplir con los requisitos de producción.

Como se puede apreciar, en la aplicación del artículo 123 influyeron los vínculos locales entre las compañías mineras, la elite en el poder y los trabajadores, en último plano. En esta primera etapa hubo una calma relativa y una retracción del movimiento obrero. En la década de 1930 se consolidó el sindicato en Cananea (Sariego, 1988, p. 173), y es probable que la combatividad de sus mineros atrajera la atención de las autoridades y de la empresa, y fuera sofocada por la vía institucional, cuestión que de alguna manera explica que una de las representaciones de las juntas de conciliación se estableciera en dicho mineral (Sariego, 1988, p. 164).

Ante este panorama poco alentador de los trabajadores de Cananea, en El Boleo y Pilares de Nacozari el camino hacia la organización sindical fue muy temprano. En 1923 se fundó el Gran Sindicato de Obreros de Santa Rosalía (Romero, 1991, p. 254), y dos años después el Sindicato Obrero de Pilares (El Látigo, 1925). El de Santa Rosalía se enfrentó a una serie de barreras en su intento por ser reconocido. En la huelga de 1925 intervino el gobierno federal y su resultado fue la obtención del primer contrato colectivo de trabajo (Romero, 1991, p. 265). 
Además, la incorporación del sindicato de El Boleo a la Confederación Regional Obrera Mexicana (CROM), en 1926, fue muestra de las estrategias que los trabajadores emprendieron para contrarrestar las acciones de la compañía al no cumplir con el contrato colectivo firmado tras la huelga de 1925 (Romero, 1991, p. 293). Un año después, en Cananea surgió el Sindicato de Oficios Varios “Nueva Orientación” (Monteón, 2006, p. 19). En su organización embrionaria y consolidación experimentaron las primeras señales del proceso de cooptación que vendría después a mayor escala, con la promulgación del Código Federal del Trabajo y el auge de las uniones obreras nacionales. Está pendiente un estudio regional sobre los vínculos que pudieron existir entre las agrupaciones mineras del noroeste. En la prensa obrera, como era el caso del periódico Regeneración, del Partido Liberal Mexicano, en sus primeros años, era común encontrar noticias sobre los acontecimientos relevantes de los centros mineros, a la par de la movilidad de la fuerza de trabajo, por medio de un circuito establecido.

Los trabajadores chilenos, en un contexto donde no hubo una revolución social como la mexicana, vivieron las dos primeras décadas del siglo XX entre la formación de los sindicatos mineros (libres) y las confederaciones obreras (Barría, 1971, p. 50), el surgimiento de los partidos de izquierda, así como la implantación y la dificultad para poner en práctica una serie de leyes laborales a causa de los vaivenes políticos en el gobierno nacional. Para la industria del cobre, este periodo significó la consolidación de las empresas en los espacios mineros. En 1923, la Chilex en Chuquicamata, fue adquirida por la Anaconda Copper Mining Corporation, que implementó modificaciones y construyó instalaciones nuevas entre 1926 y 1927 (Zapata, 1979, p. 20).

Uno de los sucesos que marcaron una diferencia con los años precedentes, aunque solo en papel, fue la promulgación de una legislación social y laboral en 1924 (Miller, 1998, p. 76). En las minas, los trabajadores vieron con beneplácito estas disposiciones legales ${ }^{5}$ aunque su aplicación fue mínima, en parte por el rechazo rotundo de las empresas y por la continuidad de las medidas coercitivas contra los trabajadores que intentaban organizarse (Zapata, 1979, p. 21). En El Teniente los trabajadores trataron de crear, infructuosamente, el Sindicato

5 Estas leyes normaron los procedimientos de seguridad en el trabajo de las minas. Además, señalaban la responsabilidad de las empresas y patrones en los accidentes de trabajo, las indemnizaciones y la asistencia que los empleadores debían cubrir. Asimismo, estipulaba la duración de las jornadas laborales, los salarios y los contratos colectivos; reglamentaba el trabajo infantil y femenino, estipulaba aspectos relacionados con la higiene, la seguridad y la libertad de comercio en los minerales y la regulación de los precios en las tiendas de las empresas. En el paquete legal se hizo una distinción entre los obreros y los empleados particulares, y se elaboró una reglamentación específica para estos últimos.

En lo general, las primeras medidas legales chilenas en torno al trabajo, se pueden asociar con el Reglamento de Policía y Seguridad en los trabajos de las minas, promovida por el gobierno de Francisco I. Madero en 1912 (aplicado hasta ya entrada la década de 1920); y con algunos de los apartados del artículo 123 de la Constitución de 1917. "Ley 4,053 sobre contrato del trabajo", Chile, Imprenta Nacional, 1924, en http://www.memoriachilena.cl/archivos2/pdfs/mc0023199.pdf; Ley 4,054 Seguros de enfermedad, invalidez y accidentes de trabajo", 8 de septiembre de 1924, en http://www.memoriachilena.cl/archivos2 /pdfs/MC0023200.pdf; "Ley 4,055 Accidentes de trabajo", 8 de septiembre de 1924, en http://www.memoriachilena.cl/archivos2/pdfs/mc0023201.pdf; "Ley 4,059 de los empleados particulares", 8 de septiembre de 1924, en http://www.memoriachilena.cl/ archivos2/pdfs/mc0023203.pdf 
Industrial El Teniente, que sería independiente, de la mano de la Federación Obrera Regional de Chile y el Partido Comunista (Miller, 1998, p. 77).

Este periodo fue de preparación y resistencia del movimiento obrero en Chile, es decir, se encontraba en una segunda etapa de resistencia porque las circunstancias políticas habían cambiado. La presencia de una legislación de tipo laboral, por más parca que haya sido en su contenido y aplicación, le proporcionó al movimiento obrero el discurso legal para seguir exigiendo las viejas demandas en torno al trabajo en las minas. De manera sigilosa, el movimiento obrero se comenzó a vincular con los partidos de izquierda y las organizaciones de trabajadores más amplias: el Partido Obrero Socialista (1912), el Partido Comunista (1921) y la Federación de Obreros de Chile (1909). También se fundaron los primeros sindicatos, como el minero de El Teniente, en 1925, aunque siguiera experimentando el control y la supervisión por parte de la empresa (Miller, 1998, p. 77; Rojas, 1993, p. 135).

La resistencia y las demandas de los trabajadores mineros de los dos países continuaron con el uso estratégico de las leyes laborales respectivas. A pesar de ello el peso empresarial, el mercado internacional del cobre, que aún sostenía a las economías de enclave, así como la posición ambigua de los gobiernos nacionales y locales (para el caso mexicano) respecto a las demandas y la aplicación de la reglamentación laboral hicieron difícil el camino de los trabajadores.

\section{Camino a la institucionalización y al reavivamiento del sindicalismo minero}

A finales de la década de 1920 los efectos de la gran depresión se reflejaron en la economía de los enclaves mineros de Chile y México. La dependencia del mercado internacional provocó que las compañías tomaran medidas estratégicas para contrarrestar la crisis. El descenso de la producción de cobre desfavoreció el uso de la mano de obra, ocasionó el despido de trabajadores y reducción de salarios, lo que produjo el descontento de los mineros y coadyuvó a la formación de organizaciones sindicales empresariales y nacionales (Barría, 1971, p. 65; Sariego, 1988, p. 186).

La crisis y sus consecuencias reavivaron el movimiento laboral, que había sido golpeado por la política represiva en Chile y aletargado por el poder empresarial y las dificultades para resolver problemas gremiales por parte de los gobiernos locales en México. En Chile no se aplicaron las reformas laborales de 1924 y continuaron las prácticas tradicionales de lucha y represión entre obreros, empresas y gobierno.

Dicha postura se mantuvo entre las presidencias de Arturo Alessandri y Carlos Ibáñez; durante la segunda se echó a andar una cruzada de represión contra la izquierda, la Federación Obrera Chilena y los líderes anarquistas en un intento por contrarrestar la agitación obrera (Miller, 1998, p. 80). Las consecuencias de la crisis mundial en la economía chilena llevaron a los trabajadores a organizar huelgas como la de 1930 en El Teniente, provocada por la merma en el salario y 
por las condiciones laborales y aderezada con el rechazo a la represión constante de los militares en contubernio con las compañías (Miller, 1998, p. 79).

Con una postura camaleónica del gobierno-dictadura de Ibáñez se generaron las condiciones para que empezara la cooptación sindical del Estado. El primer paso fue la introducción del Código de Trabajo, en 1931, como una respuesta a las inquietudes de los trabajadores tras la crisis mundial, así como un intento del gobierno por "propiciar la armonía y no el conflicto entre patrones y trabajadores" pero, sobre todo, para que la clase obrera fuera respaldo para su gobierno (Rojas, 1993, p. 74).

El Código de Trabajo constituyó un parteaguas en las relaciones obrero-patronales en Chile. La aplicación de la legislación laboral renovada estuvo rodeada por una serie de escaramuzas políticas. La salida del gobierno de Ibáñez, ante el descontento general a causa del manejo de la crisis económica, la presencia fugaz de un régimen socialista de cien días, hasta el posicionamiento de Arturo Alessandri, quien mantuvo su gobierno de 1932 a 1938, y quien regresó al poder con el respaldo de los partidos de derecha, fueron las condiciones que conformaron el panorama político de la época.

Durante el gobierno de Alessandri se puso en práctica el código laboral que incorporó, de manera rotunda, a los trabajadores a un sistema de tipo corporativista en el que las relaciones entre capital y proletariado estarían mediadas por el Estado, a través de tribunales e inspecciones de trabajo y juntas de arbitraje (Miller, 1998, p. 94; Vergara, 2008, p. 58). El sindicalismo y el arbitraje se volvieron obligatorios y le dieron un duro golpe a las posturas más radicales del anarquismo. De igual forma quedaron prohibidas las declaraciones a huelga de las federaciones de toda una industria, ${ }^{6}$ solo los sindicatos de una empresa de manera individual podrían realizarlas, con lo que se limitó la formación de confederaciones de trabajadores (Vergara, 2008, p. 58).

Ante tal panorama, fue patente la formación y el fortalecimiento de los sindicatos. Entre 1930 y 1931 se fundó el Sindicato Obrero Mina, el Sindicato de Empleados de Chuquicamata, y se consolidaron los partidos de izquierda; lo que culminaría en el apoyo que se dio al Frente Popular en las elecciones de 1938 (Zapata, 1979, p. 21). Sin embargo, el reavivamiento del sindicalismo no fue del todo parejo. La eficacia de las leyes fue relativa por la resistencia frente a las limitaciones del código laboral y que orillaron a los mineros del cobre a organizar huelgas ilegales (Vergara, 2008, p. 58). Durante los primeros años del código, la violación a los derechos laborales se reflejaba en "la estrategia de sobornos a los funcionarios públicos (directa o indirecta) [que] dejaba desvalidos a los obreros desde el punto de vista legal" (Zapata, 1979, p. 24).

La institucionalización del movimiento obrero en Chile fue paulatina durante los primeros años de la aplicación de la Ley de Trabajo. Fue a finales de la década de 1930, a partir del proceso de sucesión presidencial, cuando los trabajadores-sindicatos se incorporaron a los partidos, a través de la Confederación de Trabajadores de Chile, y apoyaron a la coalición del Frente Popular y el triunfo de su candidato, Pedro Aguirre Cerda.

6 Decreto con fuerza de ley No. 0178, mayo de 1931. Biblioteca del Congreso Nacional de Chile. http://www.leychile.cl/Navegar?idNorma=4941 
Coincidió que en México hubo cambios y reformulaciones en torno a la política laboral. En 1931 se emitió, al igual que en Chile, la Ley Federal del Trabajo en el mandato de Pascual Ortiz Rubio y bajo la sombra del jefe máximo, Plutarco Elías Calles. Como ya se apuntó, en años previos se truncaron las acciones de los trabajadores en las minas debido a la ambivalencia y la complejidad de los reglamentos laborales locales, así como a la represión y los conflictos internos entre las confederaciones obreras a escala nacional. Aunque hay referencias de la incorporación de las organizaciones de trabajadores mineros a la CROM, como sucedió con el sindicato de El Boleo, en Baja California, los obreros de las industrias estratégicas estuvieron ausentes en esta confederación, que tuvo gran fuerza en la década de 1920 (Guadarrama, 1979, p. 20). Aspecto que resalta las dificultades aún persistentes en los espacios mineros, en parte por el control empresarial y el debilitamiento del movimiento obrero. ${ }^{7}$

En México, la crisis económica en los minerales de cobre condujo a los obreros a estallar huelgas en contra de los despidos masivos y la baja salarial. En los "tres tigres del norte" los trabajadores resistieron por medio del emplazamiento a huelga y los pliegos petitorios ante tales medidas. Por ejemplo, en Pilares de Nacozari el sindicato, por medio de cartas y solicitudes al gobierno federal, trató de detener el inminente paro de labores de la Moctezuma Copper, que provocó la primera diáspora de obreros hacia las tierras agrícolas de los ríos Yaqui y Mayo, que el gobierno de Sonora les ofreció como una manera de solucionar el problema de desempleo masivo. Además, una cantidad considerable de trabajadores de las minas de Arizona arribaron a los enclaves de Sonora y Baja California, como parte de una masa de desempleados expulsada a consecuencia de la crisis económica (Soltero, 1998, p. 437).

En Cananea las cosas marchaban igual, en 1932 se preveía el despido de 585 empleados a causa de la escasez de trabajo; en ese año se formó el Gran Sindicato Obrero "Mártires de 1906", integrado por obreros y empleados de la compañía (Sariego, 1988, p. 205). La creación de un sindicato único, que dejaba de lado las organizaciones por gremio o cualificación laboral, anunciaba una postura nueva frente a la negociación con la Cananea Copper Company. El contexto de la Ley Federal del Trabajo, la injerencia y mediación del gobierno federal en las negociaciones obrero-patronales le dio otros matices al movimiento obrero minero.

Frente a tal panorama, la Ley Federal del Trabajo significó un rompimiento con el vínculo que existía entre los gobiernos locales, los intereses empresariales y los trabajadores en las minas. Si con la acción directa los empleados habían conseguido ciertas prerrogativas durante toda la década de 1920, en el contexto de institucionalización de los sindicatos se abría la posibilidad de contrarrestar el poder empresarial por medio de la capacidad de organización de los mineros, con el respaldo de las leyes laborales renovadas (Sariego, 1988, p. 200).

7 Rocío Guadarrama sugiere que la CROM, a pesar de que intentó convertirse en la representante de la mayoría de los sectores obreros, no logró incorporar de manera sustancial al proletariado industrial, entre ellos los ferrocarrileros, petroleros, textileros y los mineros, sectores que tenían una larga trayectoria de combatividad y lucha obrera. 
La mecánica sindical que prosiguió bajo las leyes y el respaldo estatal, en particular durante el gobierno de Lázaro Cárdenas, se trasladó fuera de los enclaves a través de la formación de sindicatos nacionales por industria. Así, en 1934, después de una convención, celebrada en Pachuca, Hidalgo, a la que asistieron varias agrupaciones de mineros, quedó establecido el Sindicato Industrial de Trabajadores Mineros, Metalúrgicos y Similares de la República Mexicana (SITMMSRM) (Cárdenas, 1997, p. 331; Monteón, 2006, p. 19; Sariego, 1988, p. 207). A esta reunión no asistieron los representantes de El Boleo, Pilares de Nacozari ni Cananea; estos últimos adujeron la falta de dinero para viajar a la convención, y también pesó una tradición muy arraigada en la que los conflictos laborales se solucionaban o reprimían en las fronteras del enclave. La pérdida de autonomía e incorporación a la estructura nacional sindicalista fue parte de un proceso paulatino, cargado de roces y tensiones entre las organizaciones obreras locales y la estructura sindical nacional.

El SITMMSRM envió representantes a los minerales para adherir a otras organizaciones que no asistieron a la convención de 1934. Así ocurrió en Cananea ese mismo año, donde se logró que se constituyera la sección 65 (Sariego, 1988, p. 226). Tres años después, con la presencia de otro representante del SITMMSRM en El Boleo nació la sección 117 (Romero, 1991, p. 338). En el caso de Pilares de Nacozari, debido a la ausencia de un estudio detallado sobre este mineral y sus trabajadores, se puede decir que para 1946 ya pertenecía al sindicato, pues existen referencias de las reuniones que la sección 114 hacía en el cine del lugar; ${ }^{8}$ es probable que la incorporación de los trabajadores pilarenses ocurriera en la segunda mitad de los años treinta, como en Cananea y El Boleo.

\section{El estiramiento de la autonomía}

Según Romero, la incorporación del Gran Sindicato Obrero de Santa Rosalía al SITMMSRM “abría una etapa de pérdida de autonomía para la organización sindical” (1991, p. 339). Es evidente que sucedió, y es parte de lo que ha resaltado la historiografía sobre el sindicalismo obrero en general (Carr, 1982; Sariego, 1998; Zapata, 2013). Sin negar esta premisa, al observar la cooptación, a través del movimiento obrero en sus especificidades, es posible matizar y, sobre todo, complejizar dicho proceso. El estiramiento de la autonomía sindical fue latente en el caso de los mineros del cobre en el noroeste mexicano tras agruparse al sindicato nacional, por medio de secciones. La marcha de estas últimas se efectuó entre la resistencia a las posturas centrales de la dirigencia sindical y a la movilización huelguística en los confines del enclave, que privilegiaba la negociación directa con la empresa y dejaba de lado las directrices nacionales.

En 1938, los trabajadores de la sección 117 de El Boleo expulsaron al asesor y representante especial del sindicato aduciendo corrupción, en el marco de un conflicto laboral con la empresa ante el intento de una baja salarial, suceso que se negoció directamente entre ésta y los empleados. En 1948, ante el retiro del

8 Documentos varios. Archivo Histórico de la Comisaría de Pilares de Nacozari, Sonora. 
subsidio de vivienda y servicios públicos, los trabajadores se organizaron y sin tomar en cuenta a la dirección sindical estallaron una huelga en rechazo al corte del suministro de energía eléctrica (Romero, 1991, pp. 339 y 342).

En el mismo sentido, el sindicato de Cananea vivió una etapa de autonomía durante el periodo de incorporación al SITMMSRM. Esta independencia fue posible gracias a la actividad sindical, caracterizada por la democracia interna de la sección y la representatividad de todos los reductos obreros. En 1936, desde la secretaría general, se decidió incorporar al sindicato nacional a la Confederación de Trabajadores de México, disposición que fue frenada por los trabajadores y sus secciones (Sariego, 1988, p. 245); ellos actuaron conforme a las necesidades directas que se les presentaban en los minerales, aunque tuvieran que pasar por encima de la dirigencia sindical y rechazar sus reglamentos.

Como señala Nicolás Cárdenas, la unificación de los sindicatos mineros, a través del SITMMSRM, no fue sencilla (1997, p. 331); en su etapa de consolidación las divisiones y las resistencias locales fueron una constante, y el estiramiento de la autonomía fue posible por el aislamiento producido en la cotidianidad de las relaciones obrero-patronales de los enclaves. Además, los efectos de la gran depresión propiciaron la combatividad de los obreros, que muchas veces no empataba con las directrices del sindicato nacional.

Es innegable que en los años treinta los logros de los trabajadores, alrededor de las leyes laborales y la proclividad del gobierno populista de Lázaro Cárdenas, fueron sumamente importantes para las condiciones de trabajo, la vida en las minas, la creación de cooperativas de consumo ${ }^{9}$ y la incursión en la vida política de los minerales, que fueron algunos de los contrastes que se pueden identificar entre este periodo y la década anterior (Romero, 1991, p. 339; Sariego, 1988, p. 237). La segunda guerra mundial, aparte de traer una bonanza económica importante para la minería del cobre provocó que el gobierno aceptara la defensa, por parte de los empresarios mineros, de "los principios del capitalismo de enclave, tratando de desconocer conquistas obreras y haciendo valer sus privilegios económicos" (Sariego, 1998, p. 20). El enclave parecía aún vigente en la medida que lo económico tomaba su importancia real frente a las políticas estatales de control en la dinámica laboral.

Las expectativas puestas en el nacionalismo promovido por Cárdenas, cuya manifestación más viva fue la expropiación petrolera en 1938, poco a poco se fueron diluyendo en el contexto del mercado internacional y de guerra que, en buena medida, permitió a las empresas sortear de forma positiva los conflictos con los sindicatos. Después de este periodo de interludio bélico, el comportamiento del movimiento obrero de las minas fue acomodando a las centrales sindicales y a la cooptación estatal en aras de la unidad nacional y la anhelada armonía (revolucionaria) entre capital y trabajo. ${ }^{10}$

9 La tienda de raya de la Cananea Copper Company fue cerrada en 1938, y sustituida por un almacén administrado por el sindicato. Lo mismo ocurrió en Pilares de Nacozari y en El Boleo; en el último se creó la cooperativa Independencia Económica, en 1939.

10 En 1954, El Boleo cerró temporalmente por la salida del capital francés, tras estar presente en la península sudbajacaliforniana por más de 70 años, y dio paso a la Compañía Santa Rosalía S. A., de capital nacional. Por otro lado, el mineral de Pilares de Nacozari, tras un paro de importancia en 1931, a causa de la depresión económica, cerró sus puertas en 1949. Después se fundó La Caridad (Oviedo y Ríos, 1997, p. 29; Romero, 1991, p. 344). 
Para el caso chileno, la autonomía estuvo sustentada en la resistencia que el movimiento obrero tuvo que experimentar durante el gobierno militar de Carlos Ibáñez, en la década de 1930, y por la incorporación de los sindicatos al aparato político de oposición izquierdista que tomó nuevos bríos durante el gobierno de Alessandri. La base obrera de estos partidos fue esencial para la coalición partidista que llevó al Frente Popular al triunfo en las elecciones de 1938 (Zapata, 1979, p. 21). En ese año, mientras se realizaba la campaña proselitista de cara a las elecciones presidenciales, la llegada del candidato Aguirre Cerda a la zona minera propició gran algarabía entre los obreros. ${ }^{11}$ Sin embargo, se le negó la entrada a la propiedad de la Chilex y a El Teniente (Zapata, 1979, p. 23).

Con una base obrera importante en el electorado, el Frente Popular triunfó en los comicios de 1938 y dio paso a un proceso de asociación con la política estatal del corto mandato de Aguirre Cerda. Un aparato de funcionarios públicos buscó ejercer los derechos de los trabajadores establecidos en el Código Laboral, y disminuyó la persecución y la represión en las organizaciones sindicales de los mineros pues, según Vergara, no todos disfrutaron de tales beneficios, como los sindicatos rurales que fueron muy reprimidos y diezmados (2008, p. 60). Sin embargo, la tuberculosis cobró la vida de Aguirre Cerda en 1941, y así terminó, de manera repentina, la experiencia de un gobierno que había estrechado lazos con el movimiento obrero.

En el contexto de la segunda guerra mundial, y durante el régimen de Juan Antonio Ríos (1942-1946) se mantuvo una política de contención del movimiento obrero, como en el caso mexicano, con la intención de evitar alteraciones en la dinámica de producción de cobre para el mercado bélico. Después de este periodo de retraimiento de las demandas, no sin huelgas y protestas de los sindicatos, el posicionamiento de Gabriel González Videla (1946-1952) en el ejecutivo nacional removió el pasado de represión contra el movimiento obrero y la izquierda.

Lo interesante de esta etapa de la vida política de Chile es que este personaje llegó al poder de la mano del Partido Radical y con el apoyo del Partido Comunista; fue un candidato popular en las minas de cobre, en Potrerillos recibió más de 60\% de los votos (Vergara, 2008, p. 70). A pesar de ello, el gobierno de González Videla dio un giro en su política popular, expulsó a todos los ministros de cuño comunista y expidió la Ley de Defensa Permanente de la Democracia (1948) con la que persiguió a sectores de tendencia izquierdista del país, reprimió protestas y desintegró las huelgas (Vergara, 2008, p. 71). La guerra fría incidió en estas medidas políticas, de una administración marcadamente anticomunista, y el movimiento obrero emprendió una lucha de resistencia ante la evidente contención violenta. La conflictividad de los sindicatos en las minas, la solidaridad de éstos y su incorporación a la Confederación de Trabajadores del Cobre (1951) y a la Central Unitaria de Trabajadores (1952) le dieron un respiro unionista a la lucha sindical.

Por otra parte, la crisis que experimentó la minería del cobre en Chile durante ese periodo provocó la revaloración de esta industria estratégica la cual, con

11 Lázaro Cárdenas visitó el mineral de Cananea durante su campaña electoral en 1939, la expectativa que generó entre los obreros fue similar a la descrita para el caso chileno (Sariego, 1988, p. 240). 
el tiempo, se amasó en un discurso nacionalista que apelaba a la defensa del mineral de capital extranjero. El movimiento obrero en Chile, a diferencia del mexicano, se consolidó por medio de la resistencia frente al capital. En el lapso analizado tuvo momentos cortos de relación positiva con el Estado, debido a los vaivenes político-ideológicos que contrastaron la dinámica electoral, económica y social del país.

\section{Consideraciones finales}

La condición de enclave construida alrededor del capital extranjero hizo de las minas en Chile y México un espacio aislado en los ámbitos geográfico y económico, respecto del contexto nacional. La dinámica vivida en estos lugares en torno a la producción y reproducción del trabajo fue muy singular. La creación de los company towns o campamentos dibujó y dinamizó la cotidianidad y la sociabilidad de los mineros. Después de luchar contra la movilidad golondrina de la fuerza de trabajo, por medio del enganche, las minas contaron con un proletariado que pese a sus diferencias (origen, profesionalización y cualificación laboral) entraron en una relación estrecha con posturas ideológicas contestatarias hacia el capital extranjero. El mutualismo y las mancomunales, como organizaciones de apoyo intergremial, adoptaron actitudes más radicales vinculadas con el anarcosindicalismo, que se reflejaron en las formas de protesta que sostuvieron al movimiento obrero en su primera fase, y que dieron pauta para el reconocimiento y la construcción de la conciencia de clase y lo que significaba ser un minero.

En las dos primeras décadas del siglo XX hubo un cambio en la postura política respecto al trabajo y los obreros. Aunque solo fuera en papel, en este periodo se dictaron las primeras leyes de corte social y laboral en los dos países. En México la revolución mexicana fue un catalizador que aceleró dichas políticas, aunque valdría la pena matizar esta postura y ver la legislación en materia laboral como parte de un proceso más amplio que se experimentó en América Latina y en el resto del mundo. Un estudio comparativo de las leyes y los códigos en materia laboral permitiría explicar dicho proceso.

A partir de la legislación laboral la intervención estatal fue más clara en las tensiones entre capital y trabajo, no obstante, la aplicación de estas reformas tuvo que esperar. En México, el gobierno no lograba la centralización deseada y el poder empresarial de las minas se coludía con las autoridades locales para contrarrestar las exigencias de los trabajadores; además de que aún se perseguía a los últimos reductos anarquistas y anarcosindicalistas y sus líderes, fue una época de aletargamiento y desaceleración de la movilización obrera. En Chile, para los mineros del cobre acceder a los posibles beneficios apuntados en las leyes de 1924 fue sumamente complicado, su lucha de resistencia contra las medidas coercitivas de las compañías y la represión estatal fue constante y más intensa que en México. A pesar de que entonces comenzaron a surgir las primeras organizaciones sindicales, el uso de formas tradicionales de protesta fueron estratégicas para la continuidad del movimiento obrero. 
Esto cambiaría con la institucionalización real del sindicalismo chileno y mexicano. La publicación de los códigos laborales, en 1931, instrumentalizó las relaciones entre los patrones y los trabajadores en cada país. Si se toma cierta distancia de la generalización, se puede decir que cierto contenido de estas leyes fue una conquista de la lucha histórica de los trabajadores, sobre todo en lo que respecta a las condiciones de trabajo, al pago de salarios, la eliminación paulatina del control directo de la empresa sobre la vida de los minerales y la mediación federal (en el caso mexicano) de las relaciones empresa y capital.

La puesta en marcha de los estatutos legales de trabajo fue diferenciada en ambos países. En México coincidió con el gobierno populista de Lázaro Cárdenas que apostó por el respaldo de las bases obreras y campesinas durante su candidatura y presidencia. En los minerales de Cananea, El Boleo y Pilares de Nacozari se crearon o revitalizaron los sindicatos, a la vez que se iniciaba un proceso de adhesión al SITMMSRM, que ocasionó tensiones y oposición a las disposiciones de cooptación y centralización, en un intento de estiramiento de la autonomía sindical. Aspecto que permite matizar y cuestionar la incidencia de las políticas posrevolucionarias y sus efectos directos sobre los trabajadores del cobre en el noroeste de México. En Chile, el apogeo del sindicalismo tuvo que esperar al triunfo electoral del Frente Popular, respaldado por los trabajadores y los partidos de izquierda. La integración del sindicalismo chileno al Estado se vio reforzada durante el gobierno del Frente Popular, bajo la figura de Aguirre Cerda. Aunque fue diezmado paulatinamente por las sucesiones presidenciales, los intereses económicos a la sazón de la segunda guerra mundial y la radicalización de las políticas de represión en el mandato de González Videla, a finales de los años cuarenta, fueron experiencias que alimentaron la autonomía del movimiento obrero.

A manera de conclusión, se puede decir que el control y posicionamiento estatal en el sindicalismo fue menor en el caso chileno. Aspecto que se explica por el vínculo estrecho entre sindicalismo y política en comparación con el mexicano, en el que existió una absorción paulatina y una eliminación de la oposición por el partido único. Los rumbos que tomaron las políticas nacionales de cada país repercutieron en la capacidad de autonomía o la ausencia de ella dentro del sindicalismo y su relación con el Estado y las empresas mineras.

La minería del cobre y sus trabajadores en México y Chile han transitado por un proceso histórico sumamente importante, que permite explicar en gran medida las condiciones actuales de los obreros, su organización y relación con los espacios mineros que conservan algunos rasgos tradicionales. Pilares de Nacozari feneció en 1949 y El Boleo estuvo a punto del cierre en 1954, pero fue rescatada y se mantuvo activa hasta 1972. Por su parte, Cananea se sostuvo después de la crisis de 1929, y en la década de 1960 comenzó con los trabajos de minería a cielo abierto, para luego entrar en el proceso de mexicanización, en 1971, cuando la Anaconda Copper Company vendió sus acciones.

En Chile, los campamentos de El Teniente, aún en funciones, ubicados en la ciudad de Sewell, fueron nombrados patrimonio de la humanidad por la Organización de las Naciones Unidas para la Educación, la Ciencia y la Cultura. En Potrerillos el cobre estaba agotado desde la década de 1940, pero la mina seguiría 
funcionando como fundidora y refinería, y en 1959 se anunció la apertura de El Salvador, un proyecto nuevo que la sustituiría. En 1960, la población de Chuquicamata comenzó a ser reubicada en Calama, una tendencia por parte de las compañías mineras por delegar al Estado la administración de los campamentos (Vergara, 2004, p. 429).

La producción del trabajo en los aspectos técnico, material, social y cultural ha definido a estas sociedades de enclave a través del tiempo. Aun cuando exista una tendencia al cierre de los campamentos mineros y su consecuente fracturación social, se han convertido en recuerdos de la memoria colectiva y de la identidad y lo que significa el trabajo en las minas, temas que se podrían analizar desde los estudios comparados.

\section{Referencias}

Barría, S. J. (1971). El movimiento obrero en Chile. Santiago: Ediciones de la Universidad Técnica del Estado.

Cárdenas García, N. (1997). Historia de los mineros mexicanos. 1900-1929. (Tesis de doctorado). México: Universidad Nacional Autónoma de México.

Carr, B. (1982). El movimiento obrero y la política en México 1910-1929. México: Era.

Grez Toso, S. (2007). Los anarquistas y el movimiento obrero. La alborada de "la idea" en Chile, 1893-1915. Santiago: LOM Ediciones.

Guadarrama, R. (1979). La CROM en la época del caudillismo en México, Cuadernos Políticos (29), 52-63. Recuperado de http: / /www.cuadernospoliticos. unam.mx/cuadernos/contenido/CP.20/CP20.6.RocioGuadarrama.pdf

Gutiérrez de Lara, L. (2010). Los bribones. Novela mexicana de actualidad. Hermosillo: Instituto Sonorense de Cultura.

El Látigo. (9 de agosto de 1925). Pilares de Nacozari.

Miller Klubock, T. (1998). Contested communities: class, gender, and politics in Chile's. El Teniente copper mine, 1904-1951. Durham: Duke University.

Monteón González, H. (2006). Cananea, la guerra y la buena vecindad. Hermosillo: Universidad de Sonora.

Orellana Retalmes, L. (2004). La lucha de los mineros contra las leyes: Chuquicamata (1910-1915). Historia, 37(1), 169-206.

Oviedo Ríos, P., y Ríos, P. (1997). Pilares. Sus años de ensueño. Hermosillo: Instituto Sonorense de Cultura.

Rojas Flores, J. (1993). La dictadura de Ibáñez y los sindicatos (1927-1931). Santiago de Chile: Dirección de Bibliotecas, Archivos y Museos.

Romero Gil, J. M. (1991). El Boleo, Santa Rosalía, Baja California Sur. Un pueblo que se negó a morir. Hermosillo: Universidad de Sonora.

Romero Gil, J. M. (2001). La minería en el noroeste de México: utopía y realidad, 1850-1910. Hermosillo: Universidad de Sonora y Plaza y Valdez.

Sariego, J. L. (1988). Enclaves y minerales en el norte de México. Historia social de los mineros de Cananea y Nueva Rosita, 1900-1970. México: Casa Chata. 
Sariego, J. L. (1998). El Estado y la minería mexicana. Política, trabajo y sociedad durante el siglo XX (tomo VI). México: Comisión de Fomento Minero, Instituto Nacional de Antropología e Historia y Fondo de Cultura Económica.

Soltero Contreras, M. G. (1998). Entre la realidad y la esperanza de un pueblo minero: Pilares de Nacozari y la crisis de 1929. Cuicuilco, 6(16), 435-443.

Vergara, A. (2004). Conflicto y modernización en la gran minería del cobre (19501970). Historia, 37(II), 419-436.

Vergara, A. (2008). Copper workers, international business, and domestic politics in cold war Chile. Filadelfia: The Pennsylvania University Press.

Zapata, F. (1977). Enclaves y sistemas de relaciones industriales en América Latina. Revista Mexicana de Sociología, 39(2), 719-731.

Zapata, F. (1979). Los mineros de Chuquicamata: ¿productores o proletarios? México: El Colegio de México.

Zapata, F. (2013). El sindicalismo latinoamericano. México: El Colegio de México. 